\title{
Arousal threshold in dreaming sleep
}

\author{
C. BRADLEY* and R. MEDDIS \\ Bedford College, University of London, London NW1 4NS, England
}

\begin{abstract}
Latency to arousal from dreaming sleep to a gradually increasing white noise stimulus was measured in eight volunteer Ss. Dream reports were collected immediately after arousal. Reports which included the stimulus in the dream narrative were found to be associated with higher arousal thresholds.
\end{abstract}

Freud (1954) believed that dreaming was the guardian of sleep. It preserved sleep by disguising the significance of stimuli which would otherwise produce arousal. These stimuli could originate internally (e.g., an anxiety-provoking thought) or externally (e.g., the ringing of an alarm-clock bell). People often report sleeping through an alarm because its significance was distorted by the dream.

Berger (1963) has confirmed in the sleep laboratory that external stimuli can indeed be incorporated into dreams and be interpreted as part of the dream. The possibility that this effect could raise the arousal threshold and thus "preserve" sleep has never been experimentally tested. In the present experiment, we found that white noise stimuli were less potent in producing arousal when they were incorporated into dreams.

\section{METHOD}

Eight young volunteer Ss came separately to the sleep laboratory and slept for 1 night while their sleep was monitored electrophysiologically. Ss were awakened from time to time during the night when signs of active sleep (rapid eye movement, or dreaming, sleep) were present. They were awakened by a white noise stimulus, which was gradually increased until they woke up. On arousal, they were asked to report the content of their dream, which was later assessed by a panel of independent judges to decide whether or not the arousing stimulus had been incorporated into the dream material.

The white noise stimulus was delivered through a loudspeaker in S's room. The sound intensity was gradually increased in steps of $4 \mathrm{~dB}$ every $5 \mathrm{sec}$ until $\mathrm{S}$ responded by pressing a microswitch taped to his hand. The background noise level in the room was approximately $36 \mathrm{~dB}$. The arousal threshold measures in Table 1 represent the noise intensity at the time the sleeper pressed the microswitch. The sound-intensity values refer to the sound level at S's pillow. We used white noise in preference to pure tones because we had found, in pilot work, that a tone of over $100 \mathrm{~dB}$ could be used without an arousal response if it had been increased gradually. The loudest white noise stimulus required to produce an arousal in this experiment was $86 \mathrm{~dB}$.

Electrophysiological monitoring and sleep scoring followed standard procedures (Rechtschaffen \& Kales, 1968). Arousals from active sleep were attempted whenever possible, but each arousal was preceded by at least 5 min of continuous active sleep (REM sleep).

On waking, S was asked, "Were you dreaming?" and if so, "What was the dream about?" If S reported no dream, he was

*Now at Department of Psychology, Nottingham University, NG7 2RD, England. prompted by questions such as, "Were you thinking about anything?" Such prompts were occasionally necessary but usually produced a report after a few seconds' reflection. At the end of the report, $S$ was asked, "Did the noise come into the dream?" The typed verbatim reports were given to a panel of four independent judges, who decided whether or not the stimulus had been incorporated. The criteria used by the judges included the S's own opinion concerning incorporation and the presence or absence of noise in the dream report.

\section{RESULTS}

It was an easy matter to decide whether the noise had been incorporated into the dream, as the following complete example shows: "We had to ask for more stationary and you have to fill in a form to ask for it and that noise started and my father did not know how to stop it and he picked up a file and flicked through it looking for this form and when he came to the form that would stop the noise but there wasn't a form on the file so that noise wouldn't stop" (70-dB threshold). These decisions produced unanimous agreements, except for two difficult reports, which were discarded.

The arousal thresholds are given in Table 1. Forty-three percent of the 39 retained dream reports showed incorporation of the stimulus. Such reports were accompanied by an average arousal threshold of $69.9 \mathrm{~dB}$, $10 \mathrm{~dB}$ above the threshold for nonincorporation reports.

The statistical significance of these results was assessed by computing the mean arousal threshold for both types of arousal for each S. The eight pairs of scores were compared using the Wilcoxon matched-pairs test (Siegel, 1956). The result was significant at better than the $1 \%$ level on a one-tailed test $(\mathrm{N}=8, \mathrm{~T}=1)$. Since it was not possible to control for sequence effects in this design, we checked for any systematic difference between the groups. The sequence number for each arousal was ascertained and the mean sequence number for both types of arousal for each $\mathrm{S}$ computed. These means were compared using the Wilcoxon test, as above, with a nonsignificant result $(\mathrm{N}=8, \mathrm{~T}=15)$.

\section{DISCUSSION}

The results indicate that dream reports which include the stimulus in the dream narrative are associated, to a statistically significant extent, with raised arousal 
Table 1

Arousal Threshold Values (dBA) for Dream Reports With and Without Incorporation of the Arousing Stimulus

\begin{tabular}{lllll}
\hline$S$ & \multicolumn{1}{c}{ With Incorporation } & Mean & Without Incorporation \\
\hline 1 & $59(2)$ & 59 & $72(1), 54(3), 54(4)$ & Mean \\
2 & $63(1)$ & 63 & $56(2), 54(3), 52(4)$ & 60 \\
3 & $76(1), 66(4), 53(5)$ & 65 & $52(2), 48(3), 57(6)$ & 54 \\
4 & $70(2)$ & 70 & $66(1), 51(3), 51(4), 50(5)$ & 52.33 \\
5 & $64(1), 62(3), 86(4)$ & 70.7 & $66(2)$ & 68.50 \\
6 & $70(2), 82(3)$ & 76 & $68(1)$ & 68 \\
7 & $68(2), 77(6)$ & 72.5 & $56(1), 64(2), 79(4)$ & 66.75 \\
8 & $73(3), 73(5), 69(6), 77(7)$ & 73 & 66.33 \\
Mean & 69.9 & & & 59.9 \\
\hline
\end{tabular}

Note-Values in parentheses give the sequence number of the arousal.

thresholds. These results cannot readily be attributed to time of night or arousal sequence complications. The results demonstrate the phenomenon to which Freud (1954) drew attention, that delayed arousals are associated with incorporation of the stimulus into the dream. They do not, of course, necessarily indicate that the raised threshold was the direct result of incorporation. It is possible that the process of incorporation was itself favored by the delay in awakening. In this case, the raised threshold was caused by some other variable and the probability of incorporation was increased by the continued availability of the stimulus.

The threshold difference between the two kinds of report is not dramatic, but it is large enough to prove a potential nuisance in sleep depth research. Rechtschaffen et al (1966) had noticed during pilot work that active sleep thresholds were extremely variable when stimuli of gradually increasing intensity were used. They tentatively attributed this fact to stimulus incorporation and attempted to minimize this effect by using stimuli of unchanging intensity. It has yet to be shown that any procedure can remove entirely the influence of stimulus incorporation. It follows that the dream content should be established whenever arousal thresholds from active sleep are being measured.

\section{REFERENCES}

Berger, R. J. Experimental modification of dream content by meaningful verbal stimuli. British Journal of Psychiatry, 1963, 109, 722-740.

Freud, S. The interpretation of dreams. London: George Allen \& Unwin, 1954. Pp. 233ff).

Rechtschaffen, A., Hauri, P., \& Zeitlein, M. Auditory awakening thresholds in REM and NREM sleep stages. Perceptual \& Motor Skills, 1966, 22, 927-942.

Rechtschaffen, A., \& Kales, A. A manual of standardized terminology, techniques and scoring sy stem for sleep stages of human subjects. U.S. Department of Health, Education \& Welfare, Bethesda, Maryland, 1968.

Siegel, S. Nonparametric statistics. New York: McGraw-Hill, 1956.

(Received for publication November 15, 1973; revision received March 19, 1974.) 